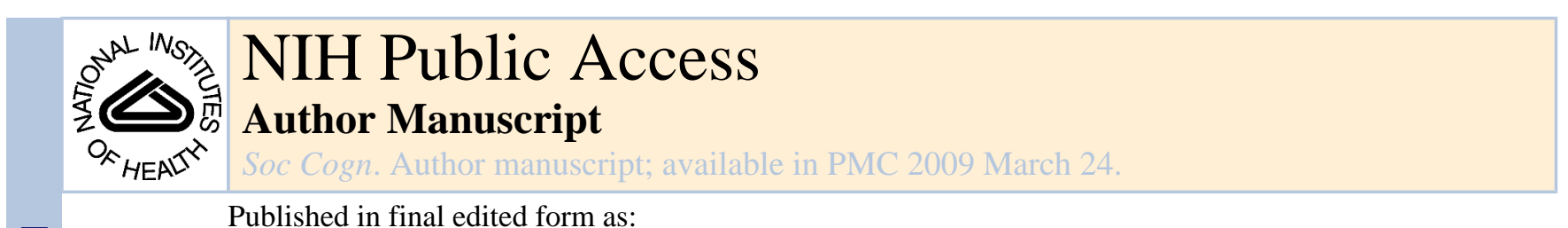

Published in final edited form as:

Soc Cogn. 2009 ; 27(1): 20-36.

\title{
Automatic and Flexible:
}

\section{The Case of Non-conscious Goal Pursuit}

\author{
Ran R. Hassin *, \\ The Hebrew University
}

John A. Bargh, and

Yale University

Shira Zimerman

The Hebrew University

\section{Abstract}

Arguing from the nature of goal pursuit and from the economy of mental resources this paper suggests that automatic goal pursuit, much like its controlled counterpart, may be flexible. Two studies that employ goal priming procedures examine this hypothesis using the Wisconsin Card Sorting Test (Study 1) and a variation of the Iowa Gambling Task (Study 2). Implications of the results for our understanding of the dichotomy between automatic and controlled processes in general, and for our conception of automatic goal pursuit in particular, are discussed.

"Control processing may be able to provide flexible control of normally inflexible automatic behavior" (Schneider, Dumais, \& Shiffrin, 1984 p. 23).

Traditionally, theories of goals and goal pursuit emphasize the role of conscious thought in goal adoption and pursuit. Thus, the process of choosing a goal is frequently assumed to involve deliberation, weighing of pros /cons, and assessing how it fits other goals, norms and values that one currently holds to be important. Successfully pursuing goals is assumed to be an effortful process too. It involves, among other things, monitoring the environment in ways that allow recognition of new opportunities and realization of blocked ones; using novel information to adapt strategies to changing circumstances, and overcoming obstacles and difficulties that thwart goal achievement. Goal pursuit, then, is not only conceived of as conscious, intentional and effortful, but also as a process that requires considerable amounts of flexibility (Ajzen, 1991; Bandura, 1986; Deci \& Ryan, 1985; Locke \& Latham, 1990).

The idea that goal choice and pursuit are controlled processed that consciously regulate behavior has been challenged in the last decade: Goals, it has been repeatedly shown, can be automatically put in motion, and they can guide behavior without ever becoming conscious (Aarts \& Dijksterhuis, 2000; Bargh, 1990; Chartrand \& Bargh, 1996; Fishbach, Friedman, \& Kruglanski, 2003; Hassin, 2005). To take a few examples, priming of a cooperation goal automatically increases participants' cooperation in a commons resource dilemma (Bargh, Gollwitzer, Lee-Chai, Barndollar, \& Troetschel, 2001). In another set of studies, priming the first names of parents -who are usually associated in their children's mind with striving for achievements - resulted in increased pursuit of achievement goals (Fitzsimons \& Bargh, 2003; Shah, 2003). Conversely, subliminally priming mothers with the name of their young

\footnotetext{
*Corresponding author Ran R. Hassin Department of Psychology The Hebrew University Jerusalem, Israel 91905 email: ran.hassin@huji.ac.il
} 
child - thereby activating the goals of nurturing and going home - resulted in decreased pursuit of achievement goals (Hassin, 2005). Importantly, these effects of goal priming occur without intention and outside of conscious awareness. Furthermore, people may be unaware of the outcomes of their automatically pursued goals (Chartrand \& Bargh, 2002).

Automatic processes in general, and automatic goal pursuit in particular, are usually conceived of as the opposite of controlled processes: They are un-intentional, non-conscious, relatively effortless, and ballistic (running to completion once started, without any further conscious direction or guidance). Their main advantage lies in freeing our very-limited-capacity consciousness from many burdens, and they thus improve the efficiency with which we cope with our complex and ever-changing environment.

The advantages of automatic processes do not come without a price tag, though: It is widely held that one of the main drawbacks of automatic processes is their rigidity, or inflexibility. Thus, Shiffrin and Schneider (Shiffrin \& Schneider, 1977) suggest that controlled processes are "easily established, altered, and even reversed by the subject," whereas automatic processes "are difficult to alter, to ignore, or to suppress once learned" (p. 127; see also Logan, 1988; Schneider, Dumais, \& Shiffrin, 1984). A similar view is pervasive in personality and social psychology. Wegner and Wenzlaff (1996), for example, argue that "Although automatization may lead to the streamlining of a process such as mental control, at the same time it may reduce its flexibility and adaptivity," (p. 473; see Bargh, 1997; Macrae, Bodenhausen, Schloerscheidt, \& Milne, 1999; Moors \& De-Houwer, 2006; Schneider et al., 1984; but see Stapel \& Blanton, 2004).

In a similar vein, dual process models that are so pervasive in social psychology (cf. Chaiken \& Trope, 1999) are usually comprised of a relatively automatic system that is inflexible in nature, and a controlled system that is more flexible (e.g., Chen \& Chaiken, 1999; Strack \& Deutsch, 2004). Even Timothy Wilson, in his excellent book "Strangers to ourselves: Discovering the Adaptive Unconscious"(Wilson, 2002), a title that seems to suggest flexible unconscious processes, appears to adhere to the view that automatic/non-conscious processes are relatively inflexible in nature (p. 49). ${ }^{1}$

\section{Flexibility and Automatic Goal Pursuit}

\section{Theoretical Considerations}

In light of the prevalent view of automatic and controlled processes, the evidence for automatic goal pursuit (henceforth: AGP) creates what seems to be a contradiction. On the one hand, it was argued above that (a) successful goal pursuit oftentimes depends on cognitive and behavioral flexibility. On the other hand, the relatively new findings just described indicate that (b) successful goal pursuit may be automatic and thus, by implication, inflexible. This is not really a contradiction because, logically, the conjunction of (a) and (b) does not entail that AGP is, or may be, flexible. Simply, it may well be the case that goal pursuits that require flexibility cannot be successfully completed in an automatic fashion. In other words, it may turn out that one of the differences between automatic and controlled goal pursuit is that the latter enables flexibility whereas the former does not. If this is indeed the case then goal pursuits are either automatic, or flexible, but not both.

Notwithstanding its logical appeal, a psychological perspective suggests that this alternative is not very plausible. Our consciousness is notoriously limited in its resources (Bargh, 1984; Kahneman, 1973). This constraint implies that controlled goal pursuits, that ex hypothesis

\footnotetext{
${ }^{1}$ The adjective "adaptive", explains Wilson (p. 23), is meant to convey the idea that "non-conscious thinking is an evolutionary adaptation."
} 
consume conscious resources, can only be used infrequently; in all other cases we are left to the virtues of automatic processing (e.g., Bargh \& Ferguson, 2000). But if AGPs are indeed inflexible, the price for relying on them may be high: since successful goal pursuit often requires flexibility, inflexible AGPs are likely to be of limited help. Put differently, in order to be truly beneficial AGPs need to be flexible.

\section{Two Definitional Notes}

Before we go on to discuss the issue of flexibility in automatic goal pursuit, we would like to offer a definition of two concepts that are central to this paper: 'goal' and 'flexibility'. First, we define 'goal' as a mental representation of a future state that one wishes to attain, and that one believes - consciously or not - that she knows how to attain (cf. Aarts, Gollwitzer, \& Hassin, 2004; Bargh, 1990; Kruglanski, 1996). Simply, if one does not wish (in one sense or another) to attain a certain future state then this future state is not one's goal; and if one does not even think s/he knows how to promote goal achievement then the wish is more fantasy than a goal.

Secondly, although at first sight 'flexibility' seems to be an innocuous concept, it is truly complex and (appropriately) context dependent. One way to conceive of flexibility is as the "capacity for ready adaptation to various purposes or conditions" (Oxford English Dictionary, italics added). Flexibility of this kind may have cognitive components (e.g., realizing that a rule that governed the environment has changed), behavioral components (e.g., altering one's behaviors accordingly), and affective ones (e.g., not resenting the new rule just because it is new).

Note that in the context of goal pursuit 'flexibility' does not necessarily entail using new means. To take an example, suppose you teach statistics and you decide to explain the logic of ANOVA in a way you never did before. You try it in class, and it turns out to be a huge success. In the following year you use this 'new' way again, alas you realize that the students are looking at you, well, in a very odd way. You can be rigid, and stick with your 'new' way of explaining ANOVA, or flexible, and go back to the old way. The adoption of new means during adaptation, then, is a sufficient condition for flexibility, but not a necessary one. Put differently, ready adaptation to new/changing environments, the core essence of flexibility, can use "old" means. \{Further discussion of the issue of flexibility in cognitive processes may be found in the section on the Wisconsin Card Sorting Test, below.

\section{Previous Findings}

The leading models of AGP are associative in nature, and they suggest at least two mechanisms that allow goal priming to increase the likelihood of goal achievement (Bargh, 1990; Kruglanski et al., 2002). First, goal priming enhances the use of proper means(Aarts et al., 2004; Bargh et al., 2001; Fishbach et al., 2003; Shah, 2003). Second, AGPs interfere with cognitions and behaviors that endanger goal achievement (Fishbach et al., 2003; Sassenberg $\&$ Moskowitz, 2005; Shah, 2003). More generally, then, an automatically pursued goal $\alpha$ increases the probability of using $\beta$ (or the degree to which it is used) when the latter is a means for achieving $\alpha$, and it decreases this probability (degree) when $\beta$ interferes with goal pursuit.

Previous research on AGP provides ample evidence for the aforementioned relations between goal priming and means use. Thus, for example, Bargh and his colleagues (2001) showed that the goal of cooperation increases the likelihood of sharing resources, and Aarts and colleagues (Aarts et al., 2004; Aarts \& Hassin, 2005) showed that when participants are primed with the goal of making money they become faster, a means for getting to a task where they could earn money. ${ }^{2}$ To our knowledge, no previous study has focused on the issue of flexibility during automatic goal pursuit. 


\section{The Present Research}

We suggest that an automatically pursued goal $\alpha$ will increase flexibility when the latter improves the likelihood of goal achievement. Two studies examine this hypothesis. In Study 1 we either prime participants with an achievement goal, or not, and then use the Wisconsin Card Sorting Test (WCST; see below) to examine their adaptation to changing environmental conditions. Study 2 uses a variation of the Iowa Gambling Task (e.g. Bechara, Damasio, Tranel, \& Damasio, 1997) in order to examine our hypothesis in a different task and under different circumstances.

\section{The Wisconsin Card Sort Test}

The first study uses the WCST to measure flexibility. The WCST was originally developed to assess abstract reasoning and the ability to shift cognitive strategies in response to changing environmental contingencies (Heaton, Chelune, Talley, Kay, \& Curtiss, 1993). In fact, Berg's original paper explicitly discusses the relation between WCST and flexibility. So much so, that the paper's title is “A simple objective test for measuring flexibility in thinking"(Berg, 1948).

The WCST consists of four response cards and 128 stimulus cards that depict figures of varying colors (red, blue, yellow or green), forms (stars, triangles, circles or crosses) and numbers (one, two, three or four). In the computerized version of the WCST four response cards - one red triangle, two green stars, three yellow crosses and four blue circles - appear at the bottom of the computer screen. Participants see one stimulus card at a time, and their task is to match the stimulus card with one of the response cards. The sorting rules are either color, form or number. Participants are given feedback about the accuracy of each sorting ("right" vs. "wrong"), but never about the sorting rule. After 10 consecutive correct sortings the rule changes without prior warning, requiring the participants to use the feedback to realize that the sorting rule has changed and that a new rule should be found. In the version we used, the test continues until participants finish sorting all 128 cards.

There are a number of sub-scores of the WCST that will interest us here. First, overall correct is defined as the number of correctly sorted cards. Errors can be of two kinds. When a participant persists sorting according to a rule that is no longer valid his errors are scored as perseverative errors (there are a number of criteria for perseverance, see Heaton et al., 1993). These errors constitute a widely accept measure of flexibility (Miyake, Friedman, Emerson, Witzki, \& Howerter, 2000): The more we persevere using a strategy that is no longer working, the less flexible we are. Errors that do not match the perseverated-to principle are called nonperseverative errors. Lastly, Failures to maintain set occur when a participant makes five or more consecutive correct sortings but then makes an error before successfully completing the category.

The WCST is particularly suitable for examining mental flexibility for a number of reasons. First, since one of the motivations for its development was to assess flexibility, it captures the essence of flexible adaptation to changing environments (Berg, 1948; Demakis, 2003). The logic is simple: The structure of physical and social environments often suggests behavioral rules that, if followed, lead to better survival. Changes in environments often entail changes in these rules, and rapid adaptation to these new rules may often be important. As the description above makes clear, the structure of the WCST reflects this logic: The rules that govern sorting

\footnotetext{
${ }^{2}$ It may well be the case that participants in the Aarts et al. studies (2004;2005) were flexible and used a novel means - speed - to achieve their goal. However, one could argue that (a) speed and money are associated in real life too (the faster we work the more money we make) and (b) that even if this is not the case, the flexibility in these studies was conscious: The instructions led participants to infer that speed and money are related in the experiment's environment. Thus, while these studies provide suggestive evidence, they do not unequivocally demonstrate automatic flexibility.
} 
change without a prior warning, and participants need to look for a new rule and follow it. It is clear, then, that in terms of the definition presented above, the WCST examines flexibility as ready adaptation.

Accordingly, a recent latent-variable analysis, that looked at complex cognitive tasks such as the Tower of Hanoi and the WCST, concluded that "[T] aken together, the results from the perseveration measure ... support the conclusion that the Shifting ability is a crucial component of perseverative errors in the WCST" (p. 75; Miyake et al., 2000). Since the ability to shift (strategies, attention, rules, approaches, tasks, etc.) is an important component of flexibility, these results suggest that flexibility is a "crucial factor" underlying successful performance in the WCST.

Furthermore, the WCST is one of the most frequently administered neuropsychological tests, and a recent meta-analysis concluded that it is sensitive to frontal lobe damage or dysfunction. Indeed, it is especially sensitive to damage in the dorsolateral prefrontal cortex, a region of the cortex that is known to be involved in working memory operations (Cohen et al., 1997;

Demakis, 2003; cf. Stuss et al., 2000). Working memory "allow[s] humans to comprehend and mentally represent their immediate environment, to retain information about their immediate past experience, to support the acquisition of new knowledge, to solve problems, and to formulate, relate and act on current goals" (Baddeley \& Logie, 1999 p. 28). Working memory, in other words, seems to be the seat of flexible information processing, and it also seems to play a significant role in WCST performance.

\section{Study 1 \\ Method}

Research Participants-42 NYU undergraduates (mean age 19) participated in the study in a partial fulfillment of course requirements. These included 28 females and 14 males.

\section{Materials and Tools}

Priming: The priming manipulation was carried out in what was allegedly "a first experiment", in which participants were asked to complete a word-search puzzle (see the procedure section, below). In each of the two forms of the puzzle, a $10 \times 10$ matrix of letters was presented, below which appeared a list of 13 words that were embedded in the matrix. Each list contained the same set of six neutral words to be found (building, turtle, green, staple, lamp, plant), with the remaining seven words relevant (or not) to the concept of high performance. In the highperformance - goal priming condition, these words were win, compete, succeed, strive, attain, achieve, and master. In the no priming condition these words were ranch, carpet, river, shampoo, robin, hat, and window (cf. Bargh et al., 2001).

WCST: We used a computerized version of the 128 cards WCST.

Procedure-Upon arrival to the laboratory participants were greeted and seated in individual booths. They were told that their main task is relatively short, and were asked whether they mind helping the researcher with a pilot for another study. All participants agreed to participate in a "pilot study", and the experimenter gave them the word-search task. Participants were asked to find the embedded words at their own pace. After having finished the word-search task participants were thanked and asked to get ready to move to the "actual experiment" (the WCST). For all participants, the instructions for the WCST appeared on the computer screen and read as follows:

This game is a little unusual, because I am not allowed to tell you very much about how to do it. I want you to match the cards that appear in the center of the screen to 
one of the four key cards at the bottom of the screen. Click on the key card of your choice to indicate the key card you have chosen. As you match the cards, they will go to piles at the top of the screen. I cannot tell you how to match the cards, but you will receive feedback about your choices. Take as much time as you need (cf. Heaton et al., 1993).

After they had finished reading the instructions participants went on to do a 128 cards version of the WCST.

\section{Results}

Assessing awareness-Upon completion of the WCST participants were thoroughly debriefed in order to assess their awareness of the structure, hypotheses and purposes of the study. Participants were asked explicit, specific questions that tried to tap awareness and conscious control. These included (a) "what do you think was the purpose of the wordsearch" (b) "were there any common themes in the words of the word-search" (c) "do you think that the word-search affected your performance on the game (i.e., WCST) in any way? Please specify" (d) "do you think that your performance in the game would have been different had you taken it in a separate session" and (e) "what was the goal of the game (i.e., WCST)?" Only one participant guessed the purpose of the word-search task and noticed that many words were associated with achievement. His data were excluded from the analyses. No other participants suspect that the two tasks were related such that the first task might have affected their performance on the second.

WCST Performance-Participants who completed less than three categories were discarded from the analysis. There were only four such participants, and they were evenly distributed between the conditions.

A series of t-tests examined the effect of achievement priming on participants' performance. These revealed a significant effect on the number of correct answers, such that primed participants fared better than non-primed ones $(\underline{\mathrm{M}}=104.88 \underline{\mathrm{SD}}=6.97$ and $\underline{\mathrm{M}}=100.40, \underline{\mathrm{SD}}=$ 8.73, respectively), $\underline{\mathrm{t}}(35)=1.7, \underline{\mathrm{p}}<.05$ (one tailed). Crucially, primed participants made less perseverative errors $(\underline{\mathrm{M}}=10.94, \underline{\mathrm{SD}}=3.28, \underline{\mathrm{M}}=14.05, \underline{\mathrm{SD}}=3.85$, respectively), $\underline{\mathrm{t}}(35)=2.62$, $\mathrm{p}<.01$. There were no reliable differences in the number of non-perseverative errors or the number of failures to maintain sets, $\underline{\mathrm{t}}(35)<.8$.

In trying to assess how priming affects performance we measured the time (in seconds) it took participants to complete the task, and how interesting and difficult they found it. Priming did not affect any of these measures, all ts $<1.2$. Nonetheless, it is interesting to note that - if anything - primed participants seemed to be faster than nonprimed participants $\left(\underline{\mathrm{M}}_{\text {seconds }}=196\right.$ and 200, respectively). While measuring the time it took participants to complete the task is a noisy measure, it is heuristically informative: It suggests that the relative benefits in performance, on both success and flexibility, cannot be attributed to simple changes in participants' speed-accuracy trade-offs.

\section{Discussion}

As hypothesized, primed participants were better at the WCST. Importantly, experimental participants made significantly less perseverative errors, that is - achievement priming led to decreased perseverance to rules that no longer govern the environment. In other words, primed participants' adaptation to new environments was better than that of non-primed participants: They were more flexible. 
It is interesting to note that priming did not significantly change the number of failures to maintain set. This suggests that the differences between the two groups are concentrated in the period that immediately follows rule change, where flexibility is mostly needed.

\section{Study 2}

Study 2 replicates and extends the previous study by examining our hypothesis in a different task, a variation of the Iowa Gambling Task (IGT; cf. Bechara, Damasio, Damasio, \& Anderson, 1994).

\section{The lowa Gambling Task}

In this task participants make multiple selections from four decks of cards (labeled A, B, C, and D) that appear on a computer screen. Upon selection the cards "turn around" and participants see two numbers: One indicating how much facsimile money they gained by turning this card, and another indicating how much money they lost. Participants gain money on every card, but they lose money only occasionally.

The decks vary on two dimensions. First, the size of the gains: Two decks have relatively large gains while two have relatively small ones. The second dimension has to do with the losses: Two decks have relatively frequent and small losses, whereas the other two have relatively infrequent yet larger ones.

These dimensions are used to create two types of decks. The first type is comprised of two decks that have positive expected utility (henceforth: the good decks). The two are similar in that they have relatively low gains. They differ from each other in terms of the losses: Whereas one has relatively small frequent losses the other has bigger yet more infrequent ones. The decks' expected utility is identical.

In the second category there are two decks with negative expected utility (henceforth: the bad decks). The two decks in this category have relatively big gains, but whereas one has relatively small frequent losses the other has relatively large infrequent ones. Again, the expected utility of the decks is identical.

Participants are never told explicitly about the nature of the decks. They begin the study with a loan of 2,000 facsimile Shekels $(\sim 500)$, and a bar on the screen tracks their monetary situation throughout the experiment.

\section{The lowa Gambling Task, Tweaked}

The most notable change we introduced to this task is an implicit change in the structure of the environment. More specifically, participants made 500 choices overall, and after 250 choices - and unbeknownst to participants - all of the decks changed locations. Thus, for example, the good deck with the relatively big infrequent losses moved from being the leftmost deck to being second from the right (see Figure 1). We will refer to the first 250 trials as Environment 1, and the latter 250 as Environment 2.

\section{Hypothesis}

Consider the period that immediately follows the transition from Environment 1 to Environment 2. Adapting to the new environment means that one has to give up one's old understanding of the structure of the environment and behave accordingly. This adaptation should be more pronounced in frequent choices (in our case, in the choices of one's favorite deck) than in non-frequent ones, simply because the former allow you to get more frequent feedback from the environment, and are hence more sensitive to changes. To illustrate this 
point, consider the following example. Suppose that one frequently eats sashimi, but only very rarely consumes chicken curry. Suppose, furthermore, that NY (but not Delhi) has great sashimi, and that Delhi (but not NY) has great chicken curry. Given the base rates of one's behaviors, we should evidence a strong change in sashimi-eating when one travels from NY to Delhi, but more minor changes (if at all) in the consumption of chicken curry.

In the current paradigm, then, flexibility should manifest itself most strongly in the choices of one's favorite (i.e., most frequently chosen) location/deck. Consequently, our analyses focus on choices of the favorite location/deck.

\section{Method}

Since the second study was conducted in Israel, we had to identify priming words in Hebrew, and hence conducted a pilot study.

Pilot-26 participants were asked to rate 74 words in terms of their relation to achievement. The ratings scales ranged from 1 ("not at all related to achievement") to 9 ("highly related to achievement"). Seven words that were rated as highly related to achievement (all $\underline{\mathrm{Ms}}>\mathbf{8 . 8}$ ) were used as priming materials (see below).

Research Participants-64 participants - 36 females and 28 males - participated in this study either for course credit or for 15 Israeli Shekels ( $\$ 4)$. Their mean age was 23.5 years.

\section{Materials and Tools}

Priming: The priming procedure was similar to that of the first study. Priming was carried out in what was allegedly "a first experiment", in which participants completed a word-search puzzle. In each of the two conditions a $10 \times 10$ matrix of letters was presented, below which was a list of 13 words that were embedded in the matrix. Each list contained the same set of six neutral words to be found (chair, stamp, building, lamp, tree and blue), with the remaining seven words relevant (or not) to the concept of high performance. In the high-performancegoal priming condition, these words were win, aspiration, excellence, ambitious, competition, first and race. In the neutral priming condition, these words were farm, diamond, carpet, hat, window, table and topaz.

Iowa Gambling Task: For a description of the task see the introduction to this study.

Procedure-The general procedure was identical to the previous study. After having finished the "pilot study" (actually, the priming manipulation), participants went on to do the IGT, and they were given the following instructions: "As you see, there are four decks of cards on the screen: A, B, C and D. I want you to select one card at a time, from any deck that you choose. Each time you select a card it will turn around, and you will see how much money you won. I don't know how much money you will win, but you will find out as you go along. From time to time turning a card will not only yield monetary gains, but also monetary losses. I don't know when, or how much, will you lose, but you will find out as you go along. The bar that indicates your monetary status will automatically be updated with all gains and losses. You are absolutely free to switch from one deck to the other at any time, and as often as you wish. Please keep on playing until the computer stops you." (see Bechara et al., 2001).

\section{Results}

Assessing Awareness-A thorough debriefing examined participants' awareness. Two participants guessed the nature and purpose of the priming, and their data were excluded from the analyses. Two other participants did not finish their debriefing, and their data were excluded from the analyses as well. 
We also asked participants to rate how important was it for them to succeed in the task, and how important was it for them to remain flexible. No differences between the two conditions emerged, all ts <.4. We also tried to assess participants' construal of the situation by asking them about the meaning of success in this task. Their responses were coded as 1 if they were related to achievement (e.g., gaining points) and 2 if they were not. On this measure, too, no differences between the groups emerged, $\mathrm{t}<.5$. Thus, replicating our awareness assessment in the previous study, we conclude that goal pursuit in this study was non-conscious and unintentional.

Manipulation Check-Achievement priming should yield, ex hypothesis, better performance. Hence, after participants get to know the environments, those in the priming condition should do better (i.e., choose more good cards) than those in the control condition. In what follows we therefore analyze participants' performance in the last blocks (50 trials) of Environment 1 and 2.

Indeed, in the last block of Environment 1 participants in the achievement condition chose more good cards than participants in the control condition $\underline{\mathrm{M}}=37.94, \underline{\mathrm{SD}}=8.93$ and $\underline{\mathrm{M}}=$ $32.42, \underline{\mathrm{SD}}=9.66$, respectively), $\underline{\mathrm{F}}(1,58)=4.66, \underline{\mathrm{p}}<.04$. The same pattern held in the last block of Environment $2(\underline{M}=42.22, \underline{\mathrm{SD}}=10.58$ and $\underline{\mathrm{M}}=34.65, \underline{\mathrm{SD}}=16.86$, respectively), $\underline{F}(1,58)=4.28, \underline{p}<.05$. We conclude, then, that primed participants indeed fared better than those in the control group.

Flexibility During Environment Change-Participants' behavior clearly indicates that they have a favorite deck - it is the good deck with the infrequent yet relatively large losses. This deck was chosen more often than any other deck, all t $\mathrm{s}>4.1$, all $\underline{\mathrm{p}}<<.001$. In the following paragraphs we refer to this deck as the favorite deck.

Recall, that after 250 trials the environment underwent a radical change. Unbeknownst to participants, the decks "changed locations". So, for example, the location of participants' favorite deck became the location of another deck - specifically, a deck with negative expected utility and small, but relatively frequent losses (see Figure 1).

To measure participants' adaptiveness we compared their choices in the last block (50 cards) of Environment 1 to those in the first block of Environment 2. Degree of flexibility is evidenced here in the extent to which participants succeed in disengaging from the "old" location of their favorite deck.

Primed participants chose the location of the favorite deck 28.24 times on average $(\underline{S D}=19.80)$ in the last block of Environment 1, but only 18.20 times $(\underline{\mathrm{SD}}=12.05)$ in the first block of Environment 2, $\underline{\mathrm{t}}(28)=3.77, \underline{\mathrm{p}}<.002$. Control participants, however, barely altered their behavior: They went down from $20.97(\underline{\mathrm{SD}}=16.70)$ to $19.65(\underline{\mathrm{SD}}=13.98), \underline{\mathrm{t}}<1$. A repeated measures ANOVA, with Priming as a between subjects factor and Environment as a within subjects factor, indeed yielded a significant interaction, $\underline{F}(1,58)=6.31, \underline{p}<.02$. Thus, we conclude that participants in the priming condition were more flexible than those in the control condition: They more successfully disengaged from their favorite location following changes in the environment.

As the reader may note, there seems to be a difference between conditions in the last block of Environment 1. While this difference is not small, it is not statistically significant, and by no way surprising: Primed participants were expected to choose the good decks more often than controls. Furthermore, given that participants in the control condition chose their favorite deck 20 times in the last block of Environment 1, there was enough room for them to adapt their behavior (upward or, more likely, downward). The results suggest, however, that they 
practically did not adapt their behavior at all. Taken together, this evidence implies that the critical difference between the two conditions consisted of increased flexibility, or adaptiveness.

Were primed participants also better at discovering the structure of the new environment? To examine this question we analyzed participants' choices of the location that, during Environment 2, became the location of their favorite deck. During the last block of Environment 1 primed participants chose this location merely $5.06(\underline{\mathrm{SD}}=7.71)$ times on average, whereas during the first block of Environment 2 they went up to $18.93(\underline{S D}=10.84), t(28)=6.40, p<$. 001. Control participants went up from $10.03(\underline{\mathrm{SD}}=10.10)$ to $15.58(\underline{\mathrm{SD}}=12.09), \underline{\mathrm{t}}(30)=2.33$, $\mathrm{p}<.03$. And again, a repeated measures ANOVA, with Priming as a between subjects factor and Environment as a within subjects factor, revealed a significant interaction, $\mathrm{F}(1,58)=6.59$, $\mathrm{p}<.02$. These data imply that primed participants were also better at uncovering the structure of Environment 2.

Like in the previous analysis, there seems to be a difference between conditions in the last block of Environment 1. This difference is both expected (primed participants should, ex hypothesis, choose the bad decks less frequently) and significant ( $\mathrm{p}<.05)$. Since participants in the control condition chose this location merely ten times, they had plenty of room to move upward during Environment 2. Yet, as the interaction above shows, they moved much less than participants in the experimental group. As a whole, then, this evidence indicates that the critical difference between the two conditions consisted of increased flexibility.

To sum up, then, primed participants were better at disengaging from the structure of an old environment, and better at uncovering the structure of a new environment. We conclude, then, that primed participants revealed more flexibility soon after changes in their environment have occurred.

\section{General Discussion}

At the outset we discussed the important role of flexibility in goal pursuit, and portrayed two opposing views of the relation between AGP, controlled goal pursuit, and flexibility. One view, which is more consistent with traditional definitions of automatic and controlled processes, holds that controlled goal pursuit allows for flexibility whereas AGP does not. The opposing view, that is more consistent with what we know about the limitations of conscious awareness, holds that AGP, like controlled goal pursuit, may be flexible. Furthermore, this view holds that AGP may enhance flexibility when the latter facilitates goal achievement.

Two studies supported hypotheses derived from the latter view. In Study 1 priming of an achievement goal led to better performance and more flexibility on the WCST, a classic measure of adaptation to changing environments. Study 2 examined flexibility in a variation of the Iowa Gambling Task, and replicated the results of the first study in a new paradigm.

Together these findings suggest that flexibility may be enhanced by goals that one automatically pursues. Automatically pursued goals, it turns out, are not strictly bounded to predetermined scripts that limit one's ability to adaptively cope with our ever-changing surroundings. When need arises, the current results show, AGP can enhance responsiveness to changes in the environment.

\section{Revisiting the Issue of Awareness}

Participants in our studies were probably consciously pursuing multiple goals, some of which may be related to the task (e.g., speed). So why do we argue that the effects that we report are of automatic, non-conscious goal pursuit? The answer is simple. First, in all of the experiments 
we thoroughly debrief subjects, and in all of them participants are unaware of having been primed and of the consequences of this priming. In addition, a measure of goal commitment (Study 2) yields no difference between primed- and non-primed participants. In other words, although priming leads to the behavioral effects we document, it did so without altering conscious goal commitment.

While, on its own, none of the measures we report guarantees that goal pursuit is automatic or non-conscious, their combination serves as a strong evidence for automaticity and nonconsciousness. We conclude, then, that priming results in goal pursuit that is unintentional and non-conscious (for similar logic cf. Aarts et. al., 2004; Bargh et al., 2001).

\section{Within and Between Process Flexibility}

The current studies examined what might be called "within process flexibility": Only one goal was activated at any given point in time, and we looked at cases where flexibility was an important means for goal achievement. Another important way of being flexible is by demonstrating sensitivity to concurrent goals and norms (or other mental constructs that help in shaping behavior); in other words, a "between process" flexibility. Thus, for example, think about cases in which one needs to reconcile the goal of being helpful and the goal of being nice. Comfortably enough, often times the two go hand in hand. But what happens in cases where help consists of making someone aware of a major shortcoming or misbehavior? Similarly, what happens when the goal of being helpful is in conflict with an achievement goal? Attaining intimate relationships with sexual conservatism? Maintaining power with egalitarianism? Maximizing gains with fairness?

Like goal pursuit in general, solving goal-goal or goal-norm conflicts is considered to be an effortful, controlled process (Baumeister, Heatherton, \& Tice, 1994; Gollwitzer \& Brandstatter, 1997; Mischel, Shoda, \& Rodriguese, 1989; Muraven, Tice, \& Baumeister, 1998; Trope \& Neter, 1994). But the current results suggest that interactions of this sort may, under certain conditions, occur automatically; that automatic processes can be sensitive not only to changes in the environment, but also to changes in the internal environment (i.e., other mental processes). If this is indeed the case, then the reconciliation of two automatic goals or norms may occur flexibly and automatically too. In other words, under certain circumstances self-regulation and self control dilemmas that have not been resolved in the past may occur automatically too (cf. Fishbach et al., 2003). The results of Study 2 provide initial support for this suggestion: Primed participants more successfully resisted novel short-term temptations.

\section{Coda: Automatic and Controlled Processes}

In light of the research presented herein, how shall we go about thinking about the dichotomy between automatic and controlled processes? One way would be to stick with the rigid definition of automaticity (and control), and pronounce every flexible process as not automatic. If we follow this route, we may end up with a new category of processes that are unintentional, unconscious, ballistic and effortless, yet flexible. This seems unwarranted because it is an adhoc category that, to the best of our understanding, serves nothing but the wish to maintain a "pure" category of automatic and inflexible processes.

Alternatively, we may be more pliable and argue that under certain circumstances automatic processes may well be flexible (Eitam, Hassin, \& Schul, in press; Hassin, 2005; Hassin, Aarts, Eitam, Custers, \& Kleiman, in press; see also Bargh \& Huang, in press, and Bargh \& Morsella, in press). This conclusion seems to create a contradiction because, as we have argued in the Introduction, automatic processes are widely held to be inflexible (and pliability is regarded as one of the main advantages of controlled processes.) This quasi contradiction, we think, sends us back to the drawing table, to redraw the lines that separate automatic processes from 
controlled ones. Given the centrality of this dichotomy in the cognitive sciences (Hassin, Uleman, \& Bargh, 2005) this road promises to be fascinating, challenging and rewarding.

\section{References}

Aarts H, Dijksterhuis A. The automatic activation of goal-directed behaviour: The case of travel habit. Journal of Environmental Psychology 2000;20(1):75-82.

Aarts H, Gollwitzer P, Hassin RR. Goal Contagion: Perceiving is for pursuing. Journal of Personality and Social Psychology 2004;87(1):23-37. [PubMed: 15250790]

Aarts, H.; Hassin, RR.; Forgas, JP.; Kipling, DW.; Von Hipple, W. Social motivation: Conscious and unconscious processes. Psychology press; New York: 2005. Automatic goal inference and contagion: On pursuing goals one perceives in other people's behavior.

Ajzen, I. Attitudes and thought systems. In: Wyer, RJ.; Srull, TK., editors. The content, structure, and operation of thought systems. Advances in social cognition. Vol. 4. Lawrence Erlbaum Associates; Hillsdale, NJ: 1991. p. 79-86.

Baddeley, AD.; Logie, RH. Working memory: The multiple-component model. In: Miyake, A.; Shah, P., editors. Models of working memory: Mechanisms of active maintenance and executive control. Cambridge University Press; New York, NY: 1999. p. 28-61.

Bandura, A. Social foundations of thought and action: A social cognitive theory. Upper Saddle River; NJ: Prentice-Hall: 1986.

Bargh, JA. Automatic and conscious porcessing of social information. In: Wyer, RSJ.; Srull, TK., editors. Handbook of Social Cognition. Lawrence Erlbaum Associates; Hillsdale, NJ: 1984.

Bargh, JA. Auto-motives: Preconscious determinants of social interaction. In: Higgins, ET.; Sorrentino, RM., editors. Handbook of motivation and cognition: Foundations of social behavior. Vol. 2. Guilford Press; New York, NY: 1990. p. 93-130.

Bargh, JA. The automaticity of everyday life. In: Wyer, RJ., editor. The automaticity of everyday life: Advances in social cognition. Vol. 10. 1997. p. 1-61.

Bargh JA, Ferguson MJ. Beyond Behaviorism: On the automaticity of higher mental processes. Psychological Bulletin 2000;126(6):925-945. [PubMed: 11107883]

Bargh JA, Gollwitzer P, Lee-Chai A, Barndollar K, Troetschel R. The automated will: Non-conscious activation and pursuit of behavioral goals. Journal of Personality and Social Psychology 2001;81(6): 1014-1027. [PubMed: 11761304]

Bargh, JA.; Huang, JY. The Selfish Goal. In: Moskowitz, GB.; Grant, H., editors. Goals. Guilford Press; New York: in press

Bargh JA, Morsella E. The unconscious mind. Perspectives on psychological science. in press

Baumeister, RF.; Heatherton, TF.; Tice, DM. Losing control: how and why people fail at self regulation. Academic press; San Diego, CA: 1994.

Bechara A, Damasio AR, Damasio H, Anderson SW. insensitivity to future consequences following damage to human prefrontal cortex. Cognition 1994;51:7-15. [PubMed: 8039375]

Bechara A, Damasio H, Tranel D, Damasio AR. Deciding Advantageously Before Knowing the Advantageous Strategy. Science 1997;275(5304):1293-1295. [PubMed: 9036851]

Bechara A, Dolan S, Denburg N, Hindes A, Anderson SW, Nathan PE. Decision making deficits, linked to a dysfunctional ventromedial prefrontal cortex, revealed in alcohol and stimulat abusers. Neuropsychologia 2001;38:376-389. [PubMed: 11164876]

Berg EA. A simple objective test for measuring flexibility in thinking. The Journal of general psychology 1948;39:15-22. [PubMed: 18889466]

Chaiken, S.; Trope, Y. Dual process theories in social psychology. Guilford Press; New York, NY: 1999.

Chartrand TL, Bargh JA. Automatic activation of impression formation and memorization goals: Nonconscious goal priming reproduces effects of explicit task instructions. journal of Personality and Social Psychology 1996;71(3):464-478.

Chartrand, TL.; Bargh, JA. Non-conscious motivations: Their activation, operation, and consequences. In: Tesser, A.; Stapel, D., editors. Self and motivation: Emerging psychological perspectives. American Psychological Association; Washington, DC: 2002. p. 13-41. 
Chen, S.; Chaiken, S. The heuristic-systematic model in its broader context. In: Chaiken, S.; Trope, Y., editors. Dual-process theories in social psychology. Guilford Press; New York: 1999.

Cohen JD, Braver TS, Nystrom LE, Noll DC, Jonides J, Smith EE. Temporal dynamics of brain activation during a working memory task. Nature 1997;386:604-608. [PubMed: 9121583]

Deci EL, Ryan RM. The general causality orientations scale: Self-determination in personality. Journal of Research in Personality 1985;19(2):109-134.

Demakis GJ. A Meta-Analytic Review of the Sensitivity of the Wisconsin Card Sorting Test to Frontal and Lateralized Frontal Brain Damage. Neuropsychology 2003;17(2):255-264. [PubMed: 12803431]

Eitam B, Hassin RR, Schul Y. Non-conscious goal pursuit in novel environments: The case of implicit learning. Psychological Science. in press

Fishbach A, Friedman RS, Kruglanski AW. Leading Us Not Unto Temptation: Momentary Allurements Elicit Overriding Goal Activation. Journal of Personality and Social Psychology 2003;84(2):296309. [PubMed: 12585805]

Fitzsimons G, Bargh JA. Thinking of You: Non-conscious Pursuit of Interpersonal Goals Associated With Relationship Partners. Journal of Personality and Social Psychology 2003;84:148-164. [PubMed: 12518976]

Gollwitzer PM, Brandstatter V. Implementation intentions and effective goal pursuit. Journal of Personality and Social Psychology 1997;73:186-199.

Hassin RR. Automatic Nurturing. unpublished data. 2005

Hassin, RR. Non-conscious control and implicit working memory. In: Hassin, RR.; Uleman, JS.; Bargh, JA., editors. The New Unconscious. Oxford university press; New York: 2005. p. 196-225.

Hassin, RR.; Aarts, H.; Eitam, B.; Custers, R.; Kleiman, T. Non-Conscious Goal Pursuit and the Effortful Control of Behavior. In: Morsella, E.; Gollwitzer, PM.; Bargh, JA., editors. The Psychology of Action. Vol. 2. Oxford University Press; New York: in press

Hassin, RR.; Uleman, JS.; Bargh, JA., editors. The New Unconscious. Oxford university press; New York: 2005.

Heaton, RK.; Chelune, GJ.; Talley, JL.; Kay, GG.; Curtiss, G. Wisconsin card sorting test manual (revised and expanded). PAR, inc.; Lutz, FL: 1993.

Kahneman, D. Attention and Effort. Englewoods Cliff; NJ: Prentice-Hall: 1973.

Kruglanski, AW. Goals as knowledge structures. In: Gollwitzer, PM.; Bargh, JA., editors. The Psychology of action: Linking cognition and motivation to behavior. Guilford Press; NY: 1996. p. 599-618.

Kruglanski, AW.; Shah, JY.; Fisbach, A.; Friedman, RS.; Chun, WY.; Sleeth-Keppler, D. A theory of goal systmes. In: Zanna, MP., editor. Advances in experimental social psychology. Academic Press; San Diego, CA: 2002. p. 378-331.

Locke, EA.; Latham, GP. Work motivation: The high performance cycle. In: Kleinbeck, U.; Quast, HH., editors. Work motivation. Series in applied psychology. Lawrence Erlbaum Associates, Inc.; Hillsdale, NJ: 1990. p. 3-25.

Logan GD. Toward an instance theory of automatization. Psychological Review 1988;95:492-527.

Macrae CN, Bodenhausen GV, Schloerscheidt AM, Milne AB. Tales of the unexpected: Executive function and person perception. Journal of Personality and Social Psychology 1999;76(2):200-213. [PubMed: 10074705]

Mischel W, Shoda Y, Rodriguese ML. Delay gratification in children. Science 1989;244:933-938. [PubMed: 2658056]

Miyake A, Friedman NP, Emerson MJ, Witzki AA, Howerter A. The unity and diversity of executive functions and their contributions to complex "frontal lobe" tasks: A latent variable analysis. Cognitive Psychology 2000;41:49-100. [PubMed: 10945922]

Moors A, De-Houwer J. Automaticity: A theoretical and Conceptual Analysis. Psychological Bulletin 2006;132:297-326. [PubMed: 16536645]

Muraven M, Tice DM, Baumeister RF. Self control as limited resource: Regulatory depletion patterns. Journal of Personality and Social Psychology 1998;74:774-789. [PubMed: 9523419] 
Sassenberg K, Moskowitz GB. Don't stereotype, think different: Overcoming automatic stereotype activation by mindset priming. Journal of Experimental Social Psychology 2005;41:506-514.

Schneider, W.; Dumais, ST.; Shiffrin, RM. Automatic and controlled processing and attention. In: Parasuraman, R.; Davies, D., editors. Varieties of attention. Academic press; New York: 1984. p. 1-17.

Shah JY. Automatic for the people: How representations of significant others implicitly affect goal pursuit. Journal of Personality and Social Psychology 2003;84(4):661-681. [PubMed: 12703642]

Shiffrin RM, Schneider W. Controlled and automatic human information processing: II. Perceptual learning, automatic attending and a general theory. Psychological Review 1977;84(2):127-190.

Stapel DA, Blanton H. From seeing to being: Subliminal social comparisons affect implicit and explicit self evaluations. Journal of peronality and social psychology 2004;87:468-481.

Strack F, Deutsch R. Reflective and Impulsive Determinants of Social Behavior. Personality and Social Psychology Review 2004;8(3):220-247. [PubMed: 15454347]

Stuss DT, Levine B, Alexander MP, Hong J, Palumbo C, Hamer L, et al. Wisconsin Card Sorting Test performance in patients with focal frontal and posterior brain damage: effects of lesion location and test structure on separable cognitive processes. Neuropsychologia 2000;38(4):388-402. [PubMed: 10683390]

Trope Y, Neter E. Reconciling competing motive in self-evaluation: The role of self control in feedback seeking. Journal of Personality and Social Psychology 1994;66:646-657. [PubMed: 8189345]

Wegner, DM.; Wenzlaff, RM. Mental Control. In: Kruglanski, AW.; Higgins, ET., editors. Social Psychology: Handbook of Basic Principles. Guilford Press; New York: 1996.

Wilson, TD. Strangers to ourselves: Discovering the adaptive unconscious. Harvard University Press; Cambridge, MA: 2002. 
First Environment
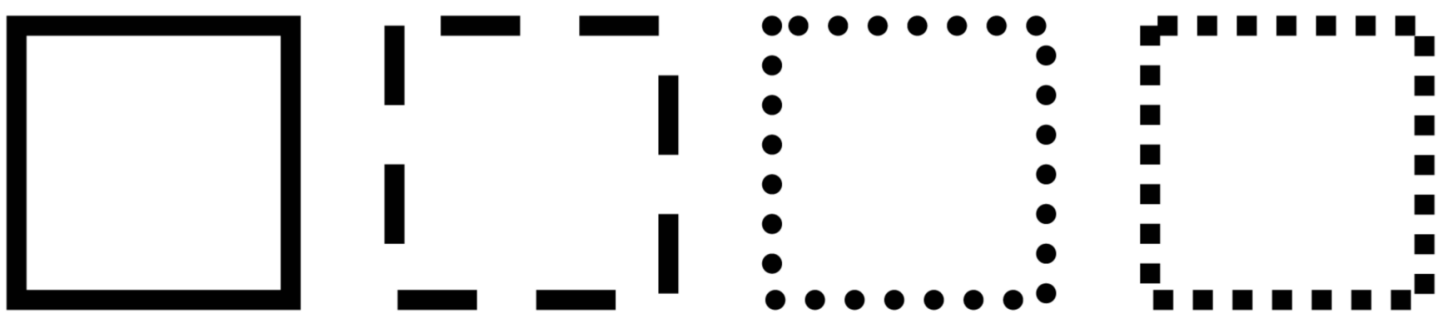

Second Environment
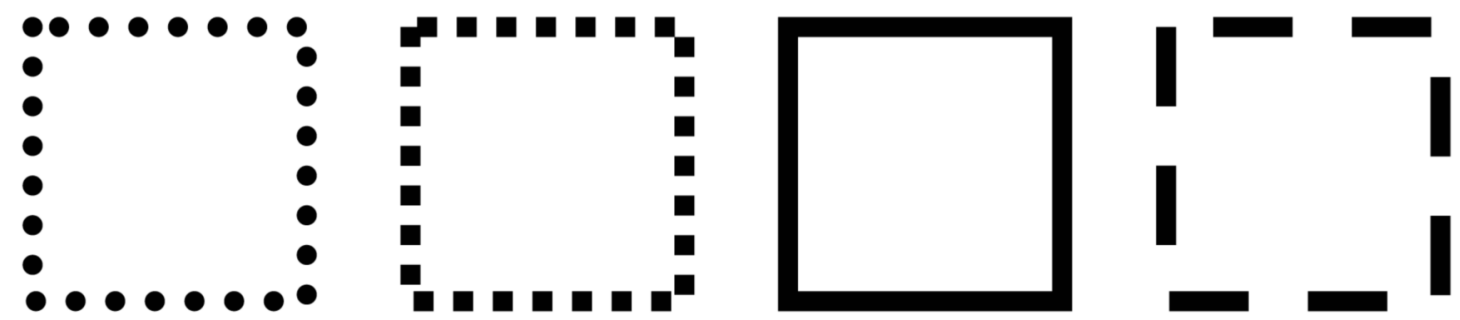

Good Deck, small losses

Good Deck, large losses

$\bullet \bullet \bullet \bullet \bullet \bullet \bullet \bullet \bullet \bullet \bullet$

Bad Deck, small losses

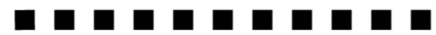

Bad Deck, large losses

Figure 1.

Locations of decks as they appeared on the screen in Study 2. Note, in the actual study the decks were indistinguishable. 